\title{
THE FUTURE OF PERSONALIZATION AT NEWS WEBSITES
}

Lessons from a longitudinal study

\section{Neil Thurman and Steve Schifferes}

This paper tracks the recent history of personalization at national news websites in the UK and US, allowing an analysis to be made of the reasons for and implications of the adoption of this form of adaptive interactivity. Using three content surveys undertaken over three and a half years, the study records-at an unprecedented level of detail-the range of personalization features offered by contemporary news websites, and demonstrates how news organizations increasingly rely on software algorithms to predict readers' content preferences. The results also detail how news organizations' deployment of personalization on mobile devices, and in conjunction with social networking platforms, is still in an early stage. In addressing the underresearched but important-and increasingly prevalent-phenomenon of personalization, this paper contributes to debates on journalism's future funding, transparency, and societal benefits.

KEYWORDS: customization; individuation; interactivity; online journalism; online news; personalization

\section{Introduction}

Although, in the US, the internet has now overtaken newspapers as a source of news (Purcell et al, 2010), the traditional newspaper-and broadcast-providers remain responsible for the bulk of news consumed online. Nearly all of the top 25 most-viewed news websites in the US are either established news brands or aggregator sites that take most of their content from existing news providers (Pew, 2011). The hopes and fears of the early analysts (for example: Negroponte, 1995; and Sunstein, 2002) that the internet's potential to democratize publishing would lead to the eclipse of traditional mass media news organizations have not been realized. Although there has been a huge increase in blogs and other forms of independent online publishing, very few are viewed by a mass audience (Hindman, 2008), and they are almost exclusively dependent on newspaper and broadcast networks for the stories they discuss (Pew, 2010a).

However, the established media face a number of challenges in relation to their internet sites; and personalization, the subject of this paper, is both a cause and a response. The challenges arise, in large part, from the consumption patterns of the online audience, and from the economics of advertising, which provides the primary means of support for online news publications. Because the online audience is relatively promiscuous (Pew, 2010b), and only stays on individual websites a short time, building loyalty has been difficult for news websites. In addition, the ability to track users as they move around the web means that advertisers can identify and target their desired upmarket audience without necessarily having to advertise on premium news websites. As a result, premium publishers have been losing advertising sales ${ }^{1}$; furthermore, as online advertising becomes more sophisticated, ${ }^{2}$ the publishers' margins are being squeezed by the companies that collect user and 
behavioural data to target advertising, and by those that host online advertising delivery platforms.

Personalization has emerged as an increasingly popular strategy for news publishers, who hope that it can increase their sites' 'stickiness', and allow them to capture data about users, thus reducing their dependence on the external suppliers of such information. ${ }^{3}$ Recent examples include The Washington Post's Trove, a site that "aggregates news and enables users to personalize their news stream based on their interests" (Lavrusik, 2011) and The New York Times-backed News.me, which "uses artificial intelligence to...learn what [people] like to read...[and] provides articles and links... of interest" (Wortham, 2011).

This paper addresses the lack of attention personalization has received from journalism scholars by recording and analysing the rate and character of its adoption by eleven national news websites in the UK and US over a three and a half year period. The first section defines the concept and lays out the taxonomy of personalization that the authors have developed. After presentation of the results, the discussion and conclusion address some of the wider issues that arise, including the economic implications of personalization for news providers, and the concernsethical, democratic, and psychological-that have surrounded personalization since the very beginning.

\section{Defining personalization}

Although personalization is often mentioned in passing as a characteristic of digital networked media, attempts to operationalize it are frequently rudimentary, with limited examples given in the literature. Where it has been studied, personalization tends to be considered as part of surveys of 'interactivity'. The features-including "moving images", "audio", and "hyperlinks" (Gerpott and Wanke, 2004: 242; Spyridou and Veglis, 2008: np) - that many such surveys consider to be 'interactive' are a long way from the "adaptive interactivity" (Deuze, 2003: 214) that this paper addresses.

We define personalization as:

A form of user-to-system interactivity that uses a set of technological features to adapt the content, delivery, and arrangement of a communication to individual users' explicitly registered and / or implicitly determined preferences.

Our approach excludes the concept of interactivity between people-for example, chat room discussions, message boards, and blogs-which has been thoroughly studied in a news context (see Thurman and Hermida, 2010). It also excludes navigational interactivity because this is a universal feature of all news websites.

The approach adopted by this paper makes an important distinction between two different types of personalization. Explicit personalization uses direct user inputs; implicit personalization infers preferences from data collected, for example, via a registration process or via the use of software that monitors user activity. Tables 1 and 2 set out the categories defined by this study-based on earlier work by Thurman (2011). 


\title{
Table 1: Taxonomy of explicit personalization functionality at news websites (reproduced from Thurman and Schifferes, 2012)
}

\author{
CATEgory Definition
}

'Email

Newsletters'

'One-to-one

Collaborative

Filtering'

'Homepage

Customization'

'Homepage

Editions'

'Mobile Editions and Apps'

'My Page'

'My Stories'

'Non-linear

Interactives'

'Other Explicit'

'RSS Feeds' *

'SMS Alerts'

'Twitter Feeds' $\dagger$

'Widgets'
Registration of individual users' email newsletter preferences. Variables include: format (HTML / plain text); delivery schedule (daily, weekly, event-triggered, etc); and choice of predetermined content categories and / or key-word / stock-symbol triggers.

Registration of preferences for content recommendations from individual journalists or other users.

Registration of content and / or layout preferences on the homepage. Differs from 'Homepage Editions' in the complexity of preferences that can be registered.

Registration of preference for an alternative version of site's homepage. For example, between regional or industry-specific editions.

Preference registration on sites' mobile editions and apps. Variables include: availability of external RSS feeds; customization by user-determined location and / or keywords or stock symbols; number of internal content modules offered; implicit preference registration \& adaptation; and possibility to save stories for repeated reading.

Registration of content preferences for a personalized page (other than the homepage). Variables include: number of internal content modules and / or stock portfolios offered; layout customization; and inclusion of external content / RSS feeds.

Ability to save stories to a personalized 'clippings' page for repeated viewing.

Embedded applications that immediately adapt their content and presentation to users' input at a level deeper than navigational control. Usually associated with, or relevant to, a specific news event, and authored using Adobe Flash. Audio-visual slide shows and other forms of non-linear information presentation that only provide temporal and / or navigational control are excluded.

System adaptation-for individual users — of content, its delivery or arrangement, based on explicitly registered preferences, not recorded elsewhere in this table.

RSS-feed availability. Variables include: number offered; format (text, video / audio); length restrictions (full and / or limited to headline and standfirst); and customization (based on user-defined keywords or combinations of predetermined categories).

Registration of individual users' preference of content category and / or keyword trigger for text message delivery.

Twitter-feed availability. Included as a technology that enables users to register to receive specific content feeds to their Twitter account.

Applications for users' desktops or for third-party sites. Examples range from the provision of specific content feeds (e.g. personalized sports results) to truly adaptive applications that allow users to locate an apartment for rent using a number of variables. $\ddagger$

${ }^{*}$ RSS feeds are included as a technology that enables users to register to receive specific content in their personal RSS reader.

† This category was not found in the previous survey.

‡ Only 'official' widgets published by the news sites surveyed have been included. 


\section{Table 2: Taxonomy of implicit personalization functionality at news websites (reproduced from Thurman and Schifferes, 2012) \\ CATEGORY \\ DEFINITION}

'Contextual

Recommendations /

Aggregations'

'Geo-targeted

Editions'

'Aggregated
Collaborative
Filtering'

'Multiple Metrics' $\dagger$

'Social Collaborative Filtering' $†$
Contextually-related content (including textual stories / blogs, videos, photo galleries, and Tweets) and links to such. Content may be internal or external. Recommendations and aggregations may be generated by software written, owned, and hosted by other organizations.

Content adaptation, most commonly on the homepage and key index pages, based on the geo-location of the user, determined by IP address or other means.

Selections of news stories or other content (such as readers' comments) automatically filtered by popularity. Variables include most: read / watched / searched / emailed. Selections may be further refined by content category (e.g. 'Politics'), user location (e.g. 'South America'), or time (e.g. 'Last 24 hours').

Adaptation of news content and presentation based on multiple, implicitlydetermined, metrics.

Content recommendations based on the behaviour of a user's social network.

$\dagger$ These categories were not found in the previous survey.

\section{Research Methods}

This study is based on three time-separated content surveys conducted between June and July 2007, between September and December 2009, and between October and December 2010. Because the 'content' to be sampled was relatively static-involving website functionality rather than the material carried-it was not necessary to undertake probalistic sampling. Instead, each website was repeatedly examined, section-by-section, and the presence of the features under investigation recorded on coding sheets. Some of the categories relating to implicit personalization were hard to measure using content analysis alone. To counter this problem, representatives of the news organizations were asked how their websites adapted content-and its delivery or arrangement-to individual users based on implicitly determined preferences.

\section{Results}

The three content surveys allowed a longitudinal analysis to be made of the deployment of personalization features at eleven news websites over a period of three and a half years. Between the first survey and the third, the total number of distinct adaptive news categories found grew by 69 percent, from 70 to 118 . The rate of growth was steady across the period: 28 percent between the first and second surveys, and 31 percent between the third and fourth (see fig 1). 
Figure 1: Growth of adaptive news at eleven national US and UK websites, 2007-10

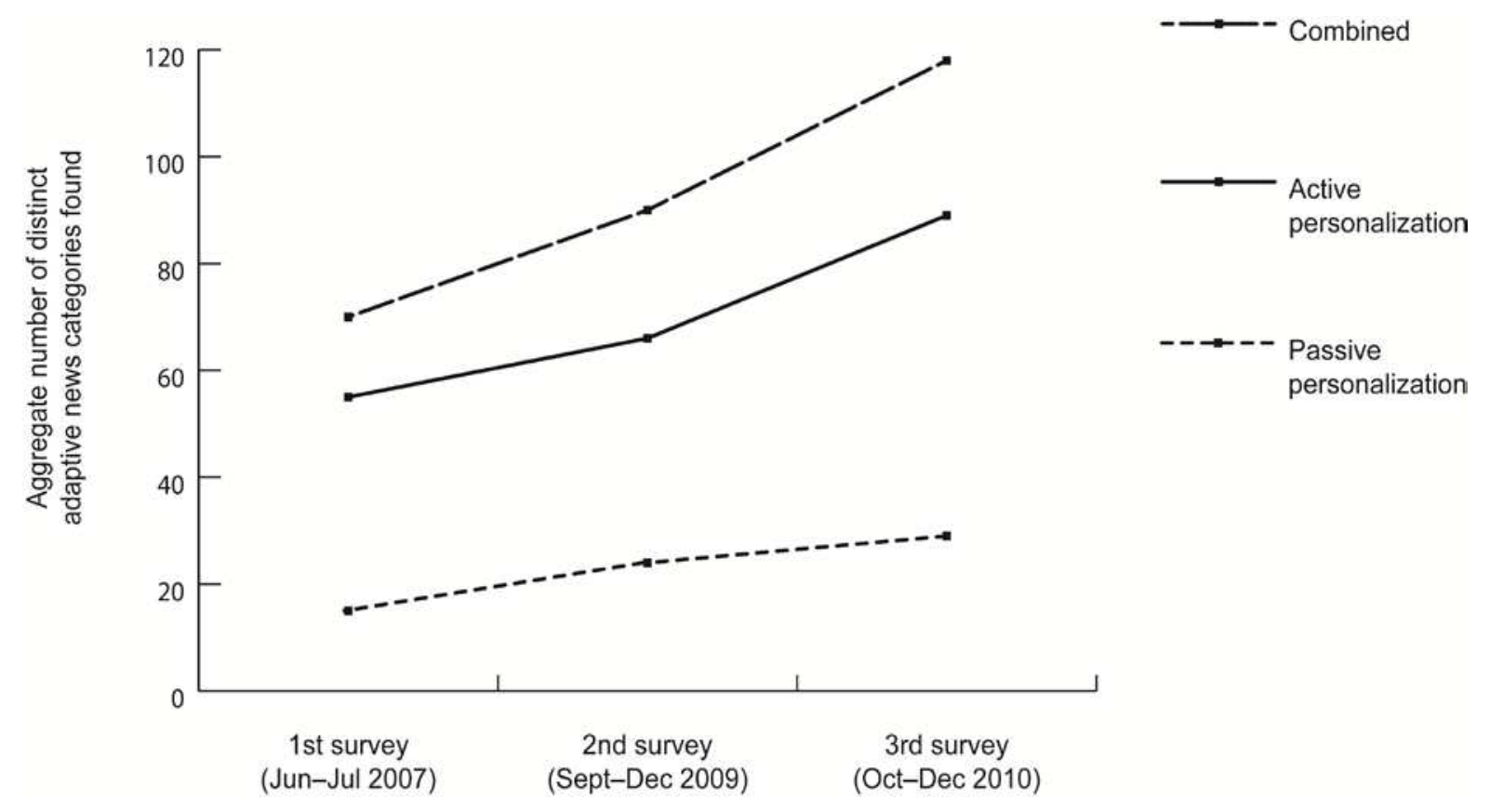

Looking at the two distinct forms of personalization-active and passive-defined by this study reveals a distinct trend: a faster rate of growth in passive personalization (98 percent) than in active personalization (62 percent).

Figures 2 and 3 show the disaggregated growth-and in some cases decline-of individual categories of passive and active personalization. Although, as has been shown, the overall picture is one of growth, this masks declines in some categories and zero growth in others. Most notably, between the first and third surveys, the occurrence of 'My Pages' fell by half from six to three. Although less pronounced, there were also negative fluctuations in the occurrence of 'Geo-targeted editions', 'Profile-based recommendations', and 'Homepage editions'. None of the remaining categories declined and some, in particular 'Twitter feeds', personalizable 'Mobile editions and apps', and 'Social collaborative filtering' exhibited significant growth during the study. 
Figure 2: Changes in deployment of active personalization features at eleven national US and UK websites, 2007-10

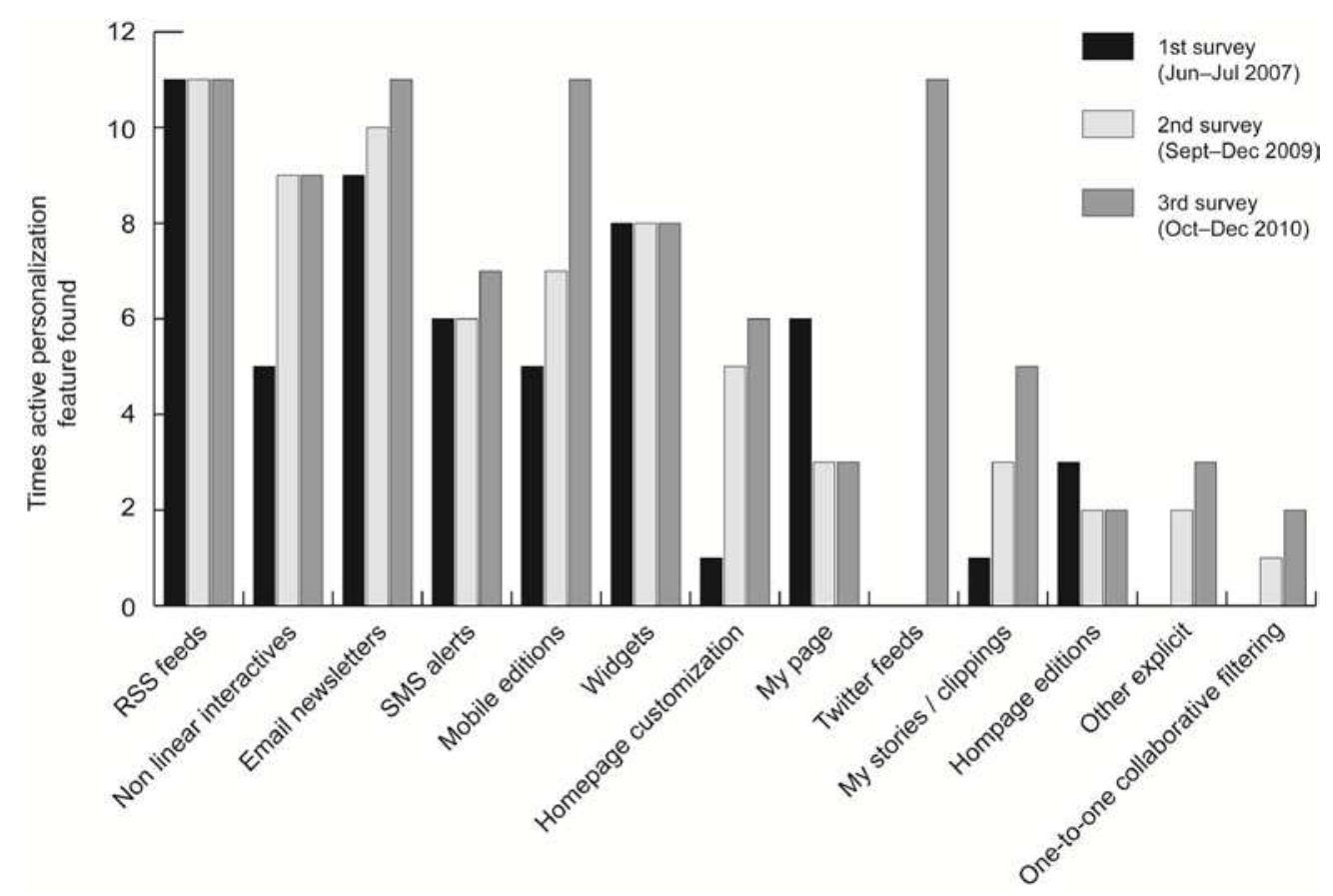

Figure 3: Changes in deployment of passive personalization features at eleven national US and UK websites, 2007-10

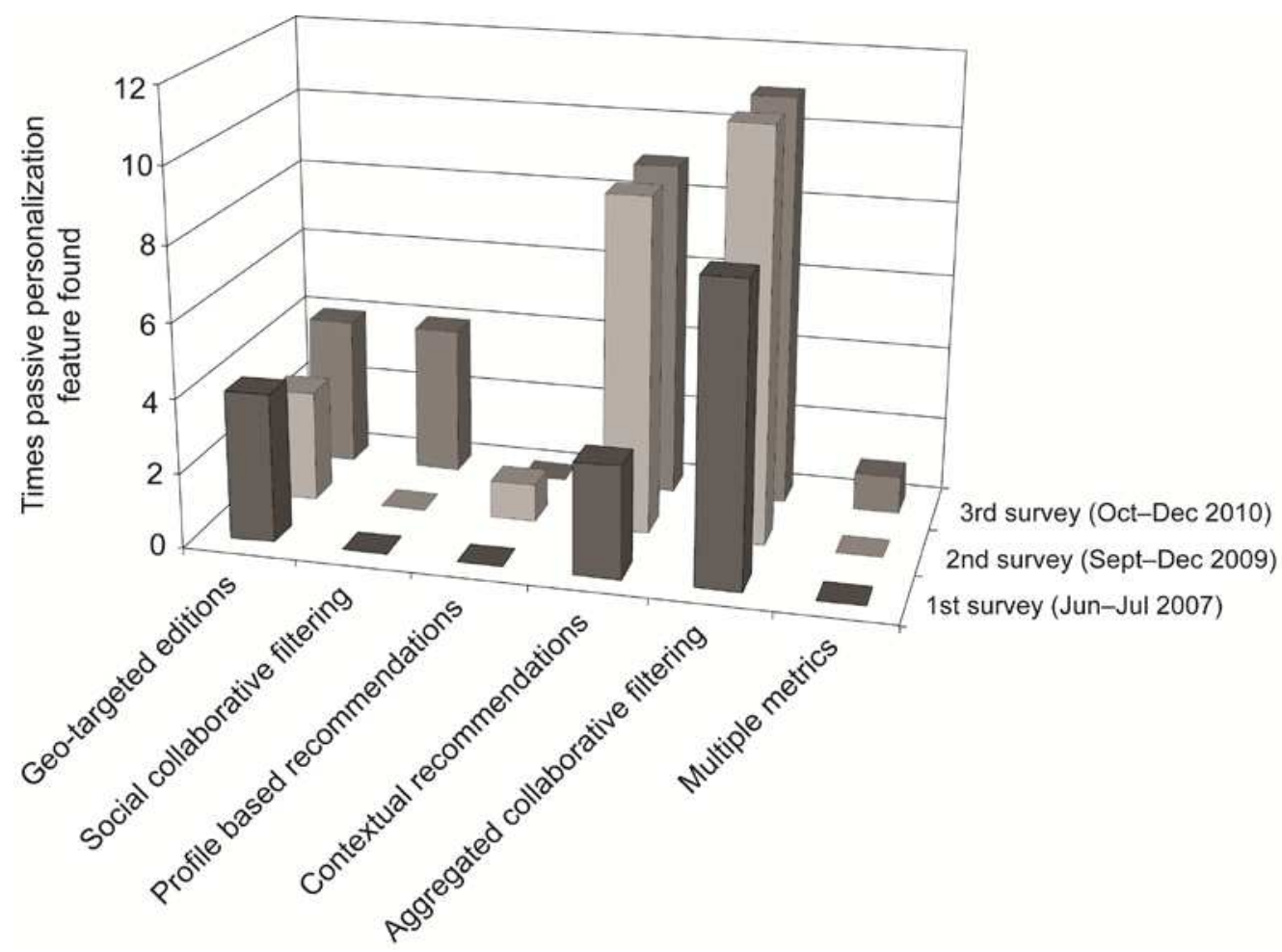


The content surveys didn't simply record whether particular categories of personalization occurred at a news website. As shown in tables 3, 4, and 5, multiple variables were recorded for over 40 percent of the categories: for example, the number of customizable 'Email Newsletters' offered by each news website and whether those newsletters could be customized by format or schedule, or by an event or keyword trigger.

From this mass of detail a number of findings are worth bringing to the fore:

- 'Social collaborative filtering', which was first detected in 2010, relies, in every case, on the Facebook 'Activity Feed' plug-in through which users can receive recommendations from their Facebook 'friends'.

- There was considerable churn in the external companies providing 'Contextual recommendations and aggregation' services to the websites surveyed. Between 2009-2010, Digg, Evri, Loomia, and Aggregate Knowledge were dropped, whilst Taboola, BackType, and KIT Digital became involved in supplying the technology used to make automated contextual recommendations to users of the sites surveyed.

- Although 'Aggregated collaborative filtering' was already ubiquitous at the time of the second survey, its deployment increased significantly in sophistication in 2010, with a 33 percent increase in the occurrence of the distinct forms of filtering supported.

- The growth in 'Personalizable mobile editions and apps' between the first and third surveys was rapid-120 percent-and universal: by the end of 2010 it was one of only five categories found at every site surveyed. The range of devices supported and the forms of personalization also increased. As table 5 shows, news providers now offer not only personalizable mobile editions of their sites but also dedicated 'apps' for Android, Blackberry, iPad, iPhone, and Palm Pre devices. News organizations provided personalizable 'apps' for an average of 2.18 devices, and six had personalizable mobile versions of their websites. However, despite this expansion, mobile editions offered far less adaptive interactivity than news providers' full web editions—by a factor of 13 .

So far this section has analyzed the survey results by comparing categories of personalization rather than by comparing news organizations. Figure 4 offers such a comparison, using the most recent-2010 — survey data in its most granular form. What emerges is evidence of:

- Above average deployment of personalization features at the two specialist financial news providers surveyed, FT.com and WSJ.com, and at three of the four sites that charged, or had announced their intention to introduce a paywall: FT.com, WSJ.com, and NYTimes.com.

- Very low prevalence of personalization at the two sites with a popular, or 'tabloid', print parent: Mirror.co.uk and theSun.co.uk. 
Figure 4: Provision of personalized news features at eleven news websites, Oct-Dec 2010

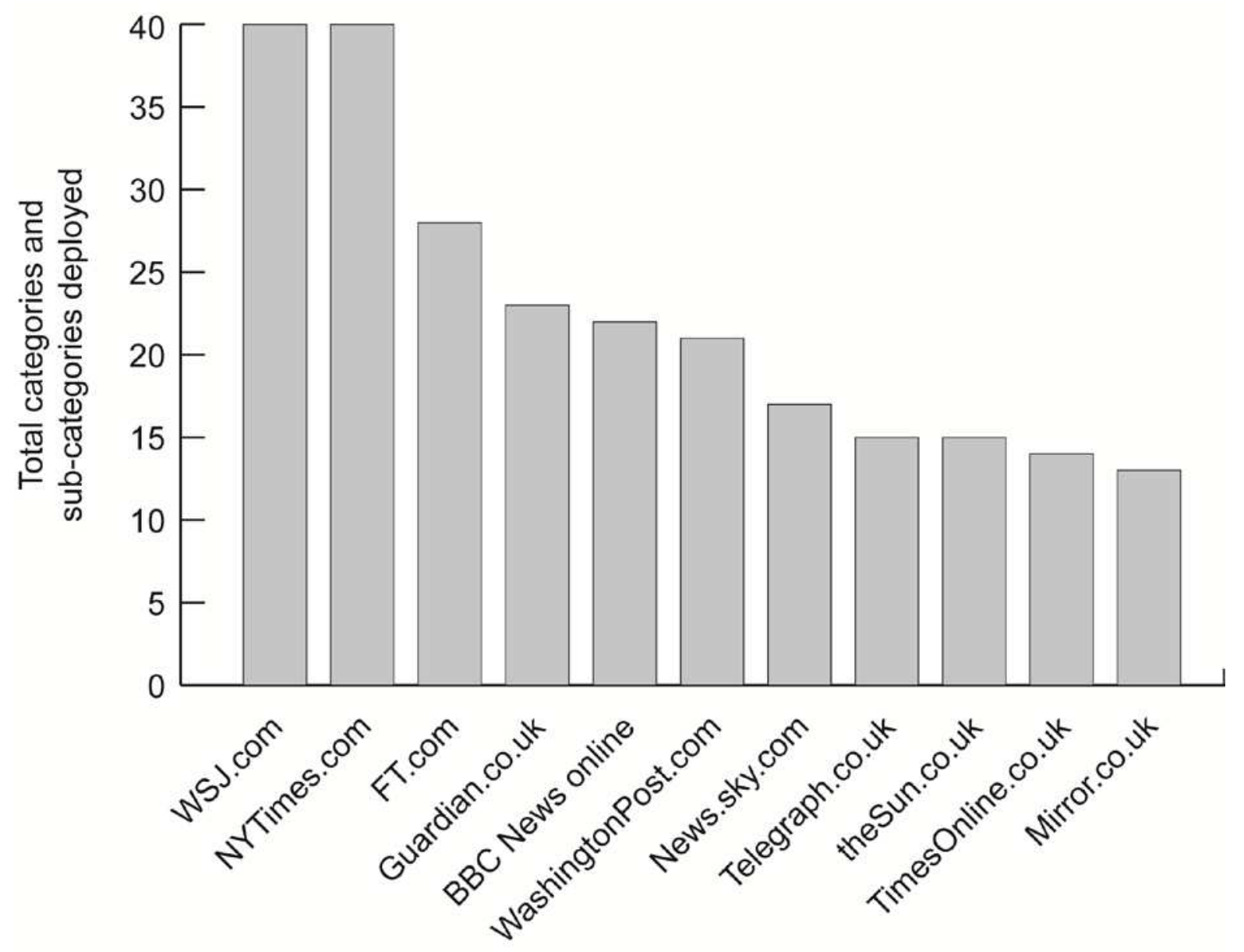

\section{Discussion}

The significant and consistent growth of personalization over the three and a half years of this study shows how the eleven legacy news providers surveyed have-as previously observed by Mitchelstein and Boczkowsi (2009)_overseen remarkable cumulative changes in their interactive products and services as they have attempted to defend against new entrants into the digital media arena and retain the attention their news brands receive in a multiplatform world.

This growth in personalization is part of a move away from traditional "commondenominator, one way" mass communication (Neuman, 1991: 42) towards a model that aligns better with the nature of internet advertising, where the importance of the cost-per-click (CPC) revenue model and the dynamic, contextually-aware, serving of advertisements means that online news providers, more than ever, need to maximize the relevance of content to individual users.

However, understanding what is relevant to each and every individual reader is a considerable challenge. Firstly, because the acquisition of news-and other mediais "still by and large a passive affair" (Harrison, 2006: 207), and secondly, even when the small number of readers who are prepared to spend time and effort personalizing 
news content (Thurman, 2011: 409) do so, systems are compromised by inaccurate reporting of interests (ibid) and by profiles remaining static despite users' interests changing over time (Gauch et al., 2007).

The reluctance of readers to engage with complex forms of active personalization is amply demonstrated by one of this study's findings: the 50 percent fall in the provision of 'My Pages', which allow users to create whole personalized pages of content. In attempting to overcome reader reluctance, news websites have, for some time (Thurman, 2011: 413), wanted to develop passive forms of personalization that infer preferences from data collected, for example, via a registration process or via the use of software that monitors user activity. This study shows that websites have acted on this intention, making passive forms of personalization the fastest growing forms during the 2007-2010 period.

However, predicting accurately what readers want at the individual level is a considerable technical challenge, especially in the news domain where the rapid turnover of content means existing forms of personalization that offer "more of the same" are not appropriate (Billsus and Pazzani, 2007). As a consequence, news sites have sought external technology and data partners-this study found a total of twelve external companies to be involved in driving contextual recommendations at the sites surveyed. We will return to the wisdom of such partnerships in the conclusion.

In this study's analysis of variation in news organizations' deployment of personalization features, we can see the influence of "organizational and institutional contexts" (see Mitchelstein and Boczkowski, 2009). This is most evident in the differences between the two specialist, paid-for financial news providers surveyedFT.com and WSJ.com-and the non-specialist, 'free-to-air', general interest, news sites. The specialist paid-for providers have, on average, deployed nearly 1.7 times more personalization features, an indication of how their readers may be more willing to bear the "psychological costs and inconvenience" (Neuman, 1991: 146) involved in finding special-interest information through active personalization. In our 2010 survey, FT.com and WSJ.com were two of only three sites-the other being NYTimes.com-to host 'My Pages', the category of active personalization that demands the highest level of interactivity from users.

One of the most dramatic changes recorded by this study is the rapid growth in personalizable 'Mobile editions and apps'. This is not surprising given the increasing number of mobile news 'apps' coming to market (PostMedia News, 2010), an increase driven by the perception that the growing numbers ${ }^{4}$ of smartphone users will want to consume news on those devices. The poor browsing capabilities of mobile devices-due to their relatively small screens and imprecise pointing devices ${ }^{5}$-and their increasing ability to be location-aware suggests they may be particularly suitable platforms for personalized information delivery. It is surprising, then, that although every site studied offered a personalizable mobile edition and / or 'app', they were, relative to news providers' main websites, remarkably static in nature, with minimal adaptive interactivity. On average, the personalizable mobile editions or apps offered just 1.7 different forms of personalization, compared with an average of 22.54 for the full web editions. This thirteen-fold difference may be explained by the fact that most of the 'apps' surveyed were first generation, but the notion that mobile media consumption devices such as the iPad are better suited to 
passive consumption (see: Doctorow, 2010) may also have contributed to their static nature.

This study recorded a significant growth in 'Social collaborative filtering', a form of passive personalization in which content recommendations are made based on the behaviour of a user's social network. This category was newly deployed by four sites in 2010: NYtimes.com, Telegraph.co.uk, WSJ.com, and WashingtonPost.com. All used the Facebook 'Activity Feed' plug-in, which displays articles that users' 'friends' have recommended. Only recommendations to articles published by the news provider are shown.

However, such collaborative filtering has disadvantages over content-based approaches to personalization in the news context. Limited evidence of overlapping interests can make recommendations difficult-the so-called 'sparse matrix problem'-and it "may take some time for stories to receive enough user feedback to lead to accurate recommendations" (Billsus and Pazzani, 2007), by which time the news agenda is likely to have moved on-the so-called 'latency problem'.

The Facebook 'Activity Feed' plug-in side-steps the 'sparse matrix' and 'latency' problems by only requiring a recommendation from a single 'friend' in a users' network, but, in doing so, forsakes the advantages of scale inherent in most collaborative filtering systems, instead relying on the-considerable-assumption that there is sufficient overlap between the interests of readers and their Facebook 'friends'.

Another problem with this form of social filtering is the infrequency with which sites' Facebook 'Activity Feeds' update. The experience of one of the authors provides anecdotal evidence here. Despite a larger than average Facebook network, he received few, infrequent recommendations: none on Telegraph.co.uk or WSJ.com's Facebook plug-ins, and just four over a six month period on WashingtonPost.com. A 2010 study helps explain this observation. Baresch et al. (2011) classified just 21 percent of links shared on Facebook as 'news' and found that just 15 percent were to online newspapers, with just under half of the Facebook users studied posting links - an average of ten-in a 3-month period. Given that the average Facebook user has 130 'friends' (Facebook, 2011), on an average day those 'friends' would-collectively-post just one new link to a story in any online newspaper.

\section{Conclusion}

News organizations' attempts to harness external social networks-like Facebookto make their sites more relevant through collaborative filtering is one recent example of a history of collaboration between established online news media and external providers of technology and user data. The attraction of such partnerships for news brands lies around the promise such companies make to deliver "the most relevant" content and advertising "individualized to the ... needs of every consumer" (Aggregate Knowledge, n.d.). Indeed some, such as Google, would prefer it if journalists simply "created the content" and left it to "people in technology...[to] worry about bringing the content to the right group...by personalization" (Krishna Bharat, quoted in Pariser, 2011: 62). Such a strategy is dangerous for news providers because utilizing such services comes at a price: squeezed advertising margins ${ }^{6}$ and 
the bolstering of 'parasitic' search providers and content aggregators such as Google.

Eli Pariser (2011: 50) has suggested that "unless newspapers...think of themselves as behavioural data companies with a mission [to produce] information about their readers' preferences" they will be "sunk". This study shows-albeit to widely varying degrees-how established national news brands are treading the path of personalization. It also shows where their zeal is wanting, particularly in utilizing mobile devices as platforms for personalized information delivery.

News organizations' increasing use of personalization, particularly of the passive variety, raises genuine questions about when and how these new-invisiblegatekeeping mechanisms are being used. Is transparency ${ }^{7}$ possible? And how well is the consumer's right to privacy protected in the globalized market for personal data?

In debates about personalization, its personal and societal effects are also often topics of discussion. Such discussions are often premised on the assumption that personalization reduces-to a critical extent-opportunities for serendipitous discovery, particularly of "what really matters" (Pariser, 2011: 75), as well as reducing exposure to alternative points of view (Sunstein, 2007: 191). The consequences, such commentators argue, may be the limitation of personal creativity, "insight and learning" (Pariser, 2011: 15), a reduction in our ability to build productive social capital (Pariser, 2011:16-17), and the weakening of deliberative democracy (Sunstein, 2007: 144).

This study provides some evidence to counter the assumptions on which these arguments are based. The news sites surveyed still predominantly offered edited selections of material with multiple opportunities for serendipitous discovery. Furthermore there was-albeit limited-evidence that one form of passive personalization-'Contextual Recommendations'-was increasing the diversity of sources referred to by mainstream news sites.

Traditional news providers, in particular newspapers, remain responsible for the vast majority of original news reporting. ${ }^{8}$ However, this important function ${ }^{9}$ is being disrupted by declining advertising revenues and by the reluctance of news consumers to pay for online content. Personalization may help slow, if not reverse, this trend: firstly, if, as this study suggests, there is a correlation between above average deployment of personalization and sites' ability to charge a subscription; and, secondly, if personalization allows traditional news providers to acquire andcrucially-control a range of data about their audience. Being in control of such data will be vital as online advertising continues to become more dynamic, targeted, and data-driven.

Although this study confirms Eli Pariser's view that "the era of personalization has begun" (2011: 3) with an inevitable—although, we argue, still modest—shift from serendipity to relevance, we disagree that giving "people what they want is a brittle and shallow civic philosophy" (Pariser, 2011: 76). If personalization helps build audiences and shift revenues from search providers, content aggregators, and other intermediaries to the 'content creators', deliberative democracy may actually be better sustained. 


\section{Acknowledgements}

The authors would like to thank Charlotte Harry and Megumi Morigami for their help in researching this article.

\section{Notes}

1. Combined total newspaper print and online advertising revenues fell each year from 2006-10 (inclusive) and continued to fall in the first quarter of 2011 (NAA, 2011).

2. In 2010 , spending in local online media on targeted display ads, which "match ... ads to the interests of individual consumers", grew by 22.2 percent whilst spending on static display ads declined by 12.7 percent (Pew, 2011).

3. Trove.com's privacy policy states that it will use "the information...that we have collected about you...to [serve] you more relevant content and advertising" (Trove, 2011).

4. 43 percent of respondents to a 2010 survey of US adults owned or regularly accessed a smartphone, iPod Touch or iPad (Chyi and Chadha, 2011).

5. The so-called '"fat finger' problem common to all touch screens...makes it hard for users to reliably hit small targets" (Nielsen, 2010).

6. Pariser (2011: 49) reports an 80 percent drop in the proportion of online advertising spend retained by publishers between 2003-10.

7. Even those behind their logic find it "nearly impossible to guess how the algorithms...shape the experience of any given user" (Pariser, 2011: 13).

8. 95 percent according to a Pew (2010c) study, with newspapers responsible for 61 percent.

9. 'Original' to the extent that 60 percent of stories in the "quality" press are "all" or "mainly" based on content from PR, news agencies, or other media (Lewis et al., 2008).

\section{References}

AGGREGATE KNOWLEDGE (n.d.) "Overview", http://www.aggregateknowledge.com/about.html, accessed 2 November, 2009.

BARESCH, BRIAN, KNIGHT, LEWIS, HARP, DUSTIN and YASCHUR, CAROLYN (2011) "Friends Who Choose Your News: An Analysis of Content Links on Facebook", paper presented at the 12th International Symposium on Online Journalism, Austin, Texas, April 1-2,

http://online.journalism.utexas.edu/2011/papers/Baresch2011.pdf, accessed 18 May, 2011.

BILLSUS, DANIEL and PAZZANI, MICHAEL (2007) "Adaptive News Access", in Peter Brusilovsky, Alfred Kobsa, and Wolfgang Nejdl (Eds), The Adaptive Web: Methods and Strategies of Web Personalization, Berlin: Springer-Verlag, pp. 550570 . 
CHYI, HSIANG IRIS and CHADHA, MONICA (2011) "News on New Devices:

Examining Multiplatform News Consumption in the Digital Age", paper presented at the 12th International Symposium on Online Journalism, Austin, Texas, April 1-2, http://online.journalism.utexas.edu/2011/papers/ChyiChadha2011.pdf, accessed 18 May, 2011.

DEUZE, MARK (2003) "The Web and its Journalisms: Considering the Consequences of Different Types of Newsmedia Online", New Media \& Society 5(2), pp. 203-230.

DOCTOROW, CORY (2010) "Why I won't buy an iPad (and think you shouldn't, either)", Boing Boing, http://boingboing.net/2010/04/02/why-i-wont-buy-an-ipad-andthink-you-shouldnt-either.html, accessed, 18 May 2011.

FACEBOOK (2011) "Statistics", Facebook.com, http://www.facebook.com/press/info.php?statistics, accessed 19 May, 2011.

GAUCH, SUSAN, SPERETTA, MIRCO. et al. (2007) "User Profiles for Personalized Information Access", in Peter Brusilovsky, Alfred Kobsa, and Wolfgang Nejdl (Eds), The Adaptive Web: Methods and Strategies of Web Personalization, Berlin: Springer-Verlag, pp. 54-89.

GERPOTT, TORSTEN J., and WANKE, HENDRIK (2004) "Interactivity Potentials and Usage of German Press-title Web Sites: An Empirical Investigation", Journal of Media Economics 17(4), pp. 241-260.

HARRISON, JACKIE (2006) News, Abingdon: Routledge.

HINDMAN, MATTHEW (2008) The Myth of Digital Democracy. Princeton: Princeton University Press.

LAVRUSIK, VADIM (2011) 'Washington Post announces personalized news aggregation site', Mashable, accessed, 25 February, 2011, http://mashable.com/2011/02/11/washington-post-trove/

LEWIS, JUSTIN, WILLIAMS, ANDREW, and FRANKLIN, BOB (2008) "A Compromised Fourth Estate?", Journalism Studies (9)1, pp. 1-20.

MITCHELSTEIN, EUGENIA, and BOCZKOWSKI, PABLO (2009) "Between Tradition and Change: A Review of Recent Research on Online News Production", Journalism: Theory, Practice \& Criticism 10(5) pp. 562-586.

NAA (2011) "Annual Newspaper Ad Expenditure", Newspaper Association of America, 1 March 2011, http://www.naa.org/Trends-and-Numbers/AdvertisingExpenditures/Annual-All-Categories.aspx, accessed 4 July, 2011.

NEGROPONTE, NICHOLAS (1995) Being Digital, London: Hodder \& Stoughton. 
NEUMAN, W. RUSSELL (1991) The Future of the Mass Audience, Cambridge: Cambridge University Press.

NIELSEN, JAKOB (2010) "iPad Usability: First Findings From User Testing", Alertbox, http://www.useit.com/alertbox/ipad.html, accessed 18 May, 2011.

PARISER, ELI (2011) The Filter Bubble, London: Penguin Books.

PEW (2010a) "New Media Old Media: How Blogs and Social Media Agendas Relate and Differ from the Traditional Press", 23 May 2010, http://www.journalism.org/node/20621, accessed 24 June, 2011.

PEW (2010b) "Audience Behavior" The State of The News Media 2010, http://stateofthemedia.org/2010/online-summary-essay/audience-behavior/, accessed 24 June, 2011.

PEW (2010c) "How News Happens", Pew Research Center, 11 January 2010, http://www.journalism.org/analysis_report/how_news_happens, accessed 5 July, 2011.

PEW (2011) "The state of the News Media 2011: An Annual Report on American Journalism: Online: Key Questions Facing Digital News", Pew Research Center, http://stateofthemedia.org/2011/online-essay/, accessed 4 June, 2011.

POSTMEDIA NEWS (2010) "Papers launch apps for Apple's iPad", Calgary Herald, http://www2.canada.com/calgaryherald/news/story.html?id=4b1c3846-aac4-4f6a9ffe-df0818af30fb, accessed 18 May, 2011.

PURCELL, KRISTEN, RAINIE, LEE, MITCHELL, AMY, ROSENSTIEL, TOM and OLMSTEAD, KENNY (2010a) "Understanding the Participatory News Consumer", Pew Internet, 1 March 2010, http://www.pewinternet.org/Reports/2010/OnlineNews.aspx?r=1, accessed 24 June, 2011.

SPYRIDOU, PASCHALIA-LIA, and VEGLIS, ANDREAS (2008) "Exploring Structural Interactivity in Online Newspapers: A Look at the Greek Web Landscape", First Monday 13(5), http://firstmonday.org/article/view/2164/1960, accessed 22 February, 2011.

SUNSTEIN, CASS (2002) Republic.com, Princeton: Princeton University Press.

SUNSTEIN, CASS (2007) Republic.com 2.0, Princeton: Princeton University Press.

THURMAN, NEIL (2011) "Making 'The Daily Me': Technology, Economics and Habit in the Mainstream Assimilation of Personalized News", Journalism: Theory, Practice \& Criticism 12(4) pp. 395-415.

THURMAN, NEIL, and HERMIDA, ALFRED (2010) "Gotcha: How Newsroom Norms are Shaping Participatory Journalism Online" in Garrett Monaghan and Sean Tunney 
(Eds) Web Journalism: A New Form of Citizenship?, Eastbourne, East Sussex: Sussex Academic Press, pp. 46-62.

THURMAN, NEIL and SCHIFFERES, STEVE (2012) "The Paradox of Personalization: The Social and Reflexive Turn of Adaptive News", in: Eugenia Siapera and Andreas Veglis (Eds), The Handbook of Global Online Journalism, Wiley-Blackwell, pagination unknown.

TROVE (2011) "Why Facebook...and our Privacy Pledge", Trove.com, 21 March 2011, http://www.trove.com/privacy, accessed 5 July, 2011.

WORTHAM, JENNA (2011) "News.Me, Social News Service, Debuts for iPad", New York Times, 20 April, http://bits.blogs.nytimes.com/2011/04/20/news-me-socialnews-service-debuts-for-ipad/, accessed 25 June, 2011.

\section{Author Contact Details:}

Neil Thurman, City University London, Department of Journalism, London, EC1V OHB. Email: n.j.thurman@city.ac.uk. Tel (until Aug 2012): +49(0)8857899970

Steve Schifferes, City University London, Department of Journalism, London, EC1V OHB. Email: steve.schifferes.1@city.ac.uk

This is a preprint of an article whose final and definitive form has been published in Journalism Studies @ 2012 Taylor \& Francis; Journalism Studies is available online at informaworld ${ }^{\mathrm{TM}}$ : http://www.tandfonline.com/doi/abs/10.1080/1461670X.2012.664341 
Table 3

Implicit personalization functionality at a selection of news websites, Oct-Dec 2010

\begin{tabular}{|c|c|c|c|c|c|c|c|c|c|c|c|c|c|c|}
\hline \multirow[b]{3}{*}{ WEBSITES } & \multirow{3}{*}{ 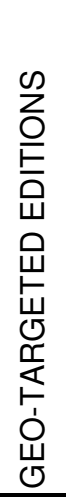 } & \multirow{3}{*}{ 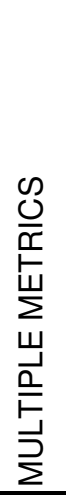 } & \multirow{3}{*}{ 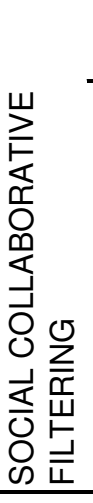 } & \multicolumn{3}{|c|}{$\begin{array}{c}\text { CONTEXTUAL RECOMMENDATIONS / } \\
\text { AGGREGATIONS } \\
\end{array}$} & \multicolumn{8}{|c|}{$\begin{array}{c}\text { AGGREGATED } \\
\text { COLLABORATIVE FILTERING } \\
\end{array}$} \\
\hline & & & & & & 节 & \multicolumn{8}{|c|}{ Sortable by: } \\
\hline & & & & & 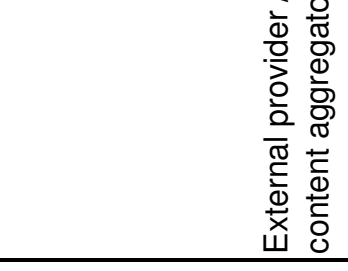 & 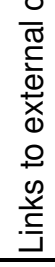 & 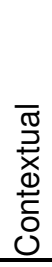 & 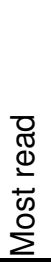 & 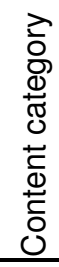 & 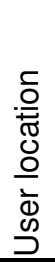 & 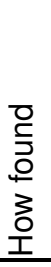 & 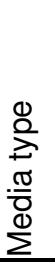 & 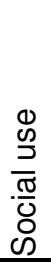 & 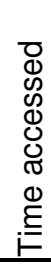 \\
\hline FT.com & $\mathrm{Y}$ & & & & & & & $\mathrm{Y}$ & $\mathrm{Y}$ & & & & & \\
\hline Guardian.co.uk & & $Y$ & & $\mathrm{Y}$ & & $\mathrm{Y}$ & & $\mathrm{Y}$ & $\mathrm{Y}$ & & & & $\mathrm{Y}$ & $\mathrm{Y}$ \\
\hline Mirror.co.uk & & & & $\mathrm{Y}$ & & & & $\mathrm{Y}$ & & & $\mathrm{Y}$ & $\mathrm{Y}$ & $\mathrm{Y}$ & \\
\hline News.bbc.co.uk & $\mathrm{Y}$ & & & $\mathrm{Y}$ & Moreover, Autonomy & $\mathrm{Y}$ & & $\mathrm{Y}$ & $\mathrm{Y}$ & $\mathrm{Y}$ & & $\mathrm{Y}$ & $\mathrm{Y}$ & $\mathrm{Y}$ \\
\hline News.sky.com & & & & $\mathrm{Y}$ & Daylife & $\mathrm{Y}$ & & $\mathrm{Y}$ & $\mathrm{Y}$ & & $\mathrm{Y}$ & $\mathrm{Y}$ & $\mathrm{Y}$ & \\
\hline NYTimes.com & $\mathrm{Y}$ & & $\mathrm{Y}$ & $\mathrm{Y}$ & Blogrunner, Taboola & $\mathrm{Y}$ & & $\mathrm{Y}$ & $\mathrm{Y}$ & & $\mathrm{Y}$ & $\mathrm{Y}$ & $\mathrm{Y}$ & $\mathrm{Y}$ \\
\hline Telegraph.co.uk & & & Y & $\mathrm{Y}$ & Autonomy, BackType & $\mathrm{Y}$ & & $\mathrm{Y}$ & $\mathrm{Y}$ & & & & & Y \\
\hline theSun.co.uk & & & & $\mathrm{Y}$ & KIT Digital & & & $\mathrm{Y}$ & & & & $\mathrm{Y}$ & $\mathrm{Y}$ & Y \\
\hline TimesOnline.co.uk & & & & & & & & $\mathrm{Y}$ & & & & & $\mathrm{Y}$ & \\
\hline WallStreetJournal.com & $\mathrm{Y}$ & & $\mathrm{Y}$ & $\mathrm{Y}$ & OneSpot & & & $\mathrm{Y}$ & $\mathrm{Y}$ & $\mathrm{Y}$ & $\mathrm{Y}$ & $\mathrm{Y}$ & $\mathrm{Y}$ & $\mathrm{Y}$ \\
\hline WashingtonPost.com & & & $\mathrm{Y}$ & $\mathrm{Y}$ & Daylife & $\mathrm{Y}$ & $\mathrm{Y}$ & $\mathrm{Y}$ & $\mathrm{Y}$ & & & $\mathrm{Y}$ & $\mathrm{Y}$ & \\
\hline
\end{tabular}


Table 4

Explicit personalization functionality at a selection of news websites, Oct-Dec 2010

EMAIL

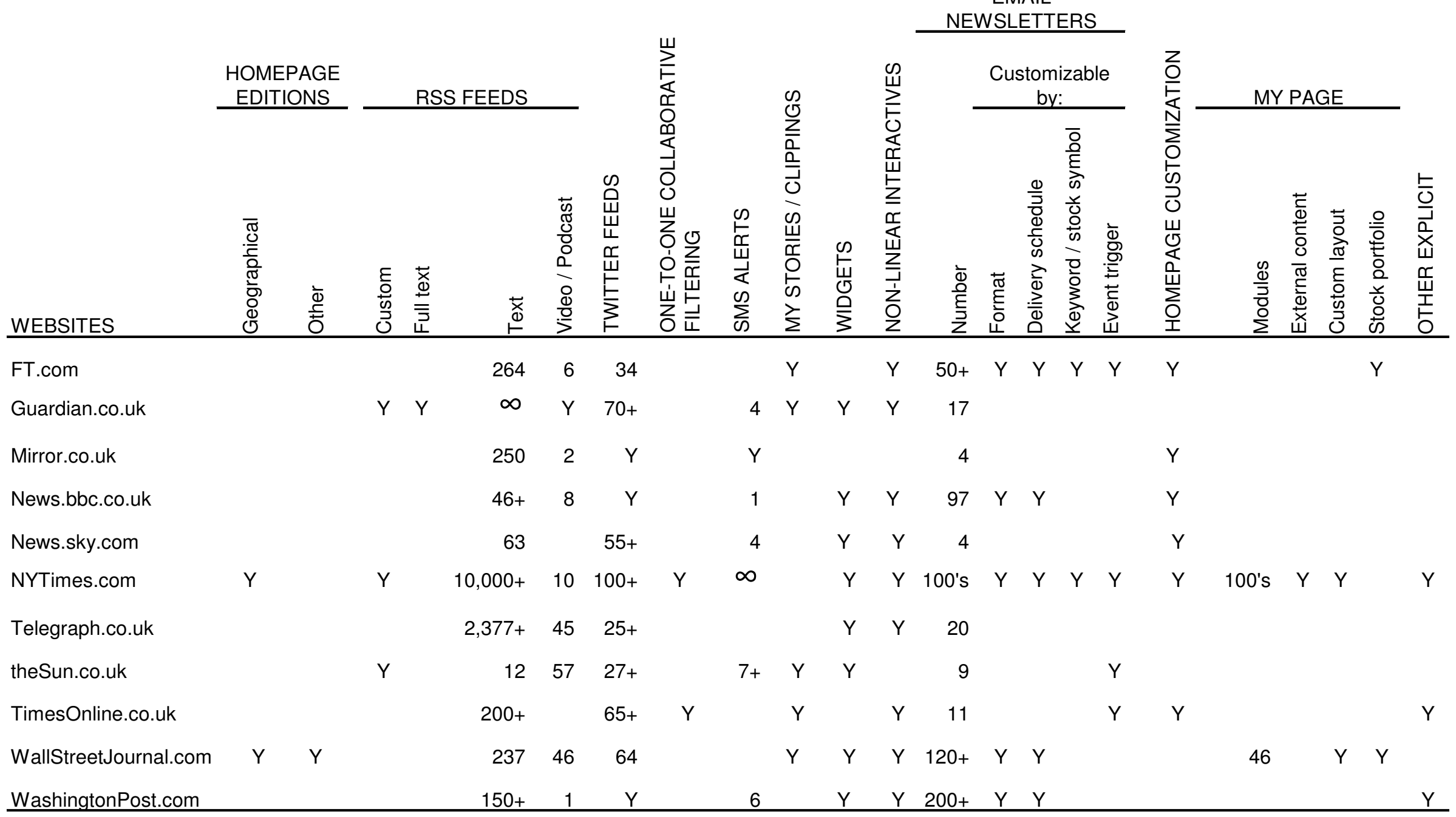

$\infty=$ Too many to count 
Table 5

Personalization functionality in news websites' mobile editions and 'apps', Oct-Dec 2010

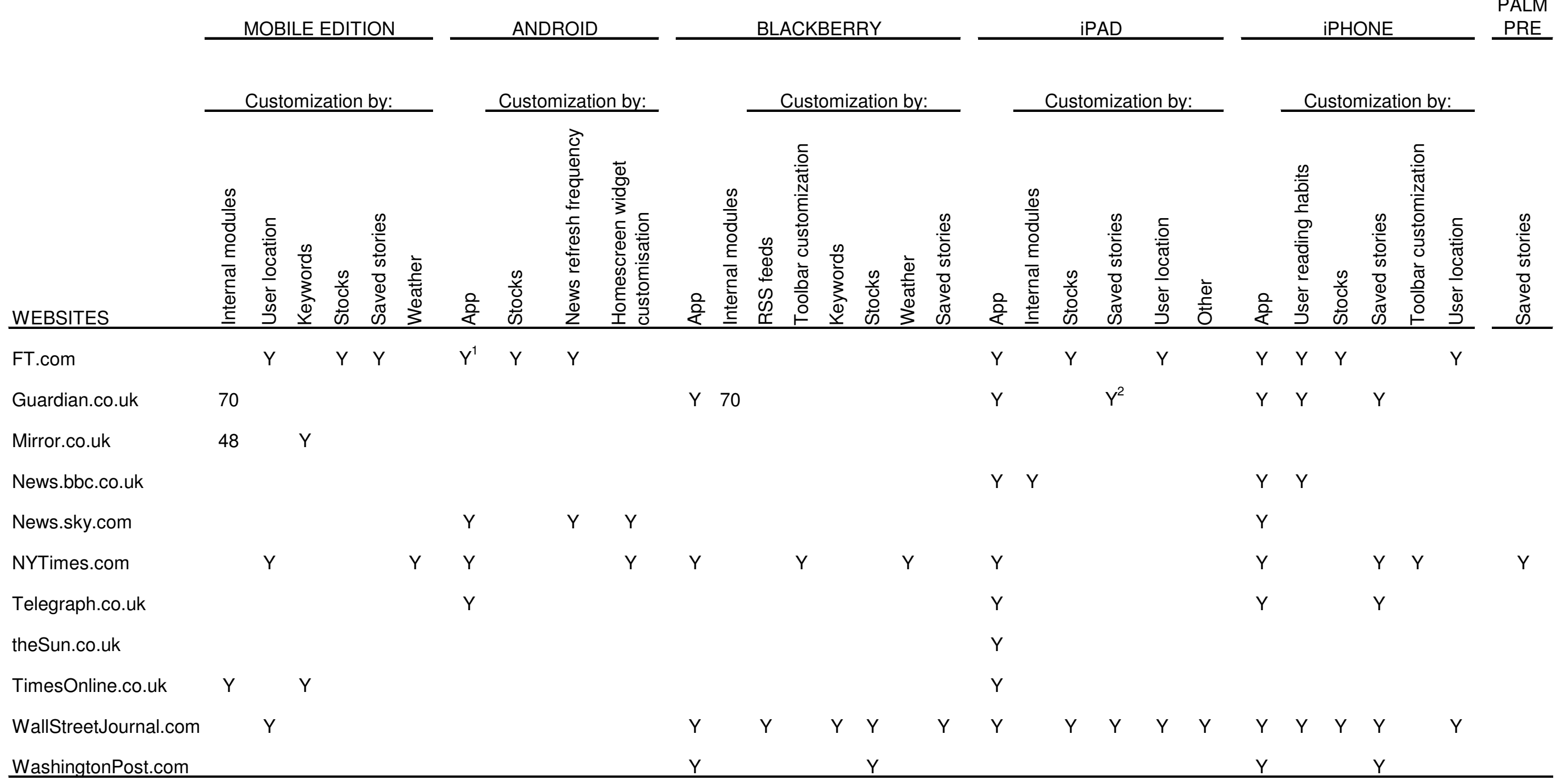

1. For the Samsung Galaxy Tab device.

2. Photos can be saved as 'favourites' in the Guardian's Eyewitness photography app.

Note: This table does not necessarily show personalization functionality available via sites' mobile editions and 'apps' already reported in tables 3 and 4 . 